\title{
¡Yllegó el bicentenario! Ciudad, clase social y vivienda en Lima (1821-2020)
}

Sección ESTUDIOS

RECIBIDO: 31/08/2020

APROBADO: 15/09/2020

PUBLICADO ONLINE: 23/10/2020

\author{
Julio Calderón Cockburn \\ Universidad Nacional Mayor de San Marcos, Perú \\ jcalderonc@unmsm.edu.pe \\ https://orcid.org/0000-0002-3623-3020
}

\section{RESUMEN}

Este artículo intenta un balance de la ciudad de Lima en su patrón de crecimiento espacial y la atención del problema de la vivienda durante el periodo republicano (1821-2020), prestando atención al proceso de desigualdad generado según las diversas clases sociales. Aborda tres periodos: 1821-1920, caracterizado por el abierto predominio del mercado en la producción de vivienda, 1921-1989 en que se definen los ejes de crecimiento de la ciudad de Lima, se establecen los patrones de segregación social y espacial, y los planteamientos del urbanismo moderno ceden paso a una visión "realista" que acepta la barriada como la "solución" a la vivienda. Finalmente, el periodo 1990-2020, representa la adopción de políticas neoliberales y un abandono, relativo, del papel del Estado, con consecuencias del fomento mayor de la informalidad y el empeoramiento de la atención de la vivienda.

PALABRAS CLAVE: vivienda; ciudad; mercado inmobiliario; informalidad; políticas públicas.

\section{And the bicentennial arrived! City, social class and housing in Lima (1821-2020)}

\section{ABSTRACT}

This article attempts a balance of the city of Lima in its pattern of spatial growth and attention to the housing problem during the republican period (1821-2020), paying attention to the process of inequality generated according to the various social classes. Addresses three periods: 1821-1920, characterized by the predominance of the free market in housing production, 1921-1989 in which the axes of the of the city are defined, the patterns of social and spatial segregation are established and the approaches of modern urbanism give way to a "realistic" vision that accepts the "barriadas" (slums) as the "solution" to housing. Finally, the period 1990-2020, represents the adoption of neoliberal policies and a relative abandonment of the role of the State, with consequences of the greater promotion of informality and the worsening of housing care. KEYWORDS: housing; city; real state; informality; public policy. 
a vivienda es una necesidad y el problema es su carencia. Como tal, es un tema vinculado pero diferente del mercado de vivienda, una vía por la cual obtener este bien, al igual que otras prácticas como la cesión y la auto producción. La vivienda es el bien más costoso que en una sociedad las familias y los individuos pueden adquirir, lo cual explica la intervención del Estado a través de la construcción de unidades habitacionales, el control de las rentas de alquileres, el planeamiento de usos de la tierra o el subsidio para la provisión de nuevas viviendas (Clapham, 2012).

La política de vivienda no solo genera efectos como mejoras en la calidad de vida, incremento de indicadores económicos (Producto Interno Bruto, entre otros), capital físico y la producción del estado del mercado de vivienda (Bourdieu, 2002); sino que, a su vez, es determinada y moldeada por agentes que presionan políticamente a través de diversos medios, legales o no (lobby, corrupción, luchas sociales, prácticas clientelares). El doble carácter de sujeto y objeto de la política requiere ser englobado en una estructura económica y social, en que las prácticas de los agentes ocurren, y en un sistema de vivienda (Stephens, 2014), el modo en que los agentes (Estado, mercado, sociedad) organizan la provisión de este bien para los habitantes.

\section{La era del mercado (1821-1920)}

Entre fines del siglo XVIII e inicios del siglo XIX, el sistema económico mundial estuvo marcado por la revolución industrial y el ascenso de Gran Bretaña como potencia mundial. La instauración por la corona española de una política de libre mercado hacia 1777 , con la creación del Virreinato del Río de la Plata, deterioró la hegemonía de Lima y las estrategias de acumulación de sus mercaderes, y sumió al virreinato en una crisis comercial. Lima era una ciudad de 400 hectáreas que se reconstruía tras el terremoto de 1746, elevándose nuevas construcciones recreativas como la plaza de toros (1768) o el Paseo de Aguas (1773).

Entre 1755 y 1820 la población de Lima había pasado de 54000 a 64000 habitantes (Flores, 1984). La estructura de las clases sociales se dividía en la aristocracia, cuyo fundamento económico era el comercio, que habitaba los barrios de San Marcelo y San Sebastián, y la plebe. La convivencia espacial no hacía sino acentuar la exclusión y la jerarquía como mecanismos de la desigualdad social (Therborn, 2015). La vida de los pocos propietarios blancos y aristócratas transcurría en salas y comedores interiores, mientras la plebe (negros e indios) se movilizaba por plazas y calles, habitando en los callejones creados hacia el siglo XVII (Stein, 1986). 
Los esclavos negros, a los que la aristocracia observaba con temor tras la revolución de Haití (1793), no necesariamente habitaban las casas de sus amos. Además del servicio doméstico, debían generar ingresos en otros oficios, lo cual les otorgaba cierta libertad de movimiento. Ocupaban casonas, callejones (cuartos de $30 \mathrm{~m}^{2}$ ) y pulperías tugurizadas, habitando un $37 \%$ de ellos en la zona de La Catedral y un 23\% en San Lázaro (Rímac), sumando 13479 personas, 26\% de la población (Flores, 1984, p. 101), detrás de los españoles (18 047) y por encima de indios y mestizos. Los indios, mayormente, se concentraban en el barrio del Cercado, originalmente un gueto fuera de la ciudad, creado en 1571 .

En los albores de la República (1821) Lima no la pasaba muy bien. A la crisis económica habría que añadir la reducción del número de esclavos. Epidemias periódicas asolaban la ciudad, como las de tifus en 1781, sarampión en 1785, 1790 y 1795 y viruela en 1802 y 1818 (Flores, 1984, pp. 102 y 105), propagándose por el desaseo reinante en una ciudad cuyas calles eran recorridas por acequias y desagües, y la basura se sedimentaba. A pesar que los médicos criollos explicaban esta situación por el ambiente físico en que se vivía, las autoridades atribuían las epidemias a los negros bozales, sometiéndolos a cuarentenas y vacunas. Hacia 1821, Lima conservaba la mentalidad señorial y las abismales diferencias en la calidad de sus viviendas.

Los cambios urbanísticos vendrían hacia la década de 1850 con la administración del presidente Castilla (1855-1862), el cual daría relevancia a la ciudad proveyendo servicios (ferrocarril, gas, agua) y reformando plazas y calles (alameda de Acho, Los Descalzos, Plaza Bolívar, Plaza Mayor), la liberación de los esclavos en 1854, y la urbanización de la zona de Las Chacaritas. El gran cambio ocurrió en 1870 con el derrumbe de las murallas de la ciudad, erigidas hacia 1685, con una ciudad que se alzaba con unos 53 mil habitantes (Muñoz, 2001, p. 38). Esta modernización fue interrumpida por la derrota de Perú en la Guerra del Pacífico (1789-1883), la cual sumió a Lima en el abandono, perdiendo, entre muertos y heridos, el 20\% de su población (Torrejón, 2010).

A fines del siglo XIX, el Perú se reinsertó en el mercado mundial, con una importante oferta diversificada de productos de exportación que dinamizaron la economía, cambios en la estructura productiva y de la propiedad, concentración de propiedad rural, desarrollo de agricultura capitalista de caña y algodón, el caucho, etcétera (Torrejón, 2010, p. 65). Lima, hacia 1891, había recuperado parte de su población, contando con unos 103 mil habitantes.

Se abrió paso a un nuevo proceso de reconstrucción y modernización de la ciudad, con el ideal de urbe moderna, individuo burgués y una concepción positivista, 
racionalista y materialista, opuesta a la mentalidad señorial, iniciado por el gobierno de Nicolás de Piérola, tras el levantamiento civil de 1894 (Muñoz, 2001). La creación del Ministerio de Fomento (1896), el ferrocarril urbano de Lima (1898), la iluminación de la ciudad (1902), el hipódromo de Santa Beatriz (1903), la expansión de la ciudad sobre las huertas (urbanización La Colmena y el Parque de la Exposición) y, allende las murallas, con el barrio de La Victoria, fueron los acontecimientos. Lima pasó de 592 hectáreas en 1870 a unas 1292 en 1908 (Muñoz, 2001) y su población de 120944 en 1876 a 172927 en 1908 (Muñoz, 2001).

En el marco de los procesos de riqueza y miseria que se generaban, el mercado y la promoción inmobiliaria (compañías urbanizadoras) empezaron a atender las demandas de las clases sociales. La clase acomodada, que se quería "extranjerizar" (A. Gamarra, en Ortega, 1986), ocupaba las casonas fastuosas del centro, con más de un patio, remodeladas estilo "americano" (Del Águila, 1997). Se ubicaban en los cuarteles 1 (Plaza de Armas a Monserrate) y 4 (Jirón Cusco hasta los límites de La Victoria), lugares céntricos, a la moda, aunque por el patrón de ciudad compacta, también allí vivía gente de bajos recursos, ubicándose 150 callejones y 339 casas de vecindad (Muñoz, 2001). Un grupo de sectores altos y medios ocupaba los edificios de departamentos construidos para viviendas múltiples, a modo de palacetes, bajo un estilo de influencia francesa, ${ }^{1}$ ubicados en la zona exclusiva de la Colmena o en el Paseo de la República.

La clase media en declive, especialmente mujeres (Parker, 1995), habitaba las casas de inquilinato o subdivididas, las cuales habían sido casonas coloniales o republicanas. Según Abelardo Gamarra El Tunante (1907), Meiggs (el promotor que destruyó las murallas), habría aconsejado a las familias ricas "que se mudaban a los nuevos barrios a subdividir sus casonas y alquilar sus diversas secciones" (Ortega, 1986, p. 104). Habitadas por una clase media que "por pretendidos respetos sociales... se alejan de los solares o callejones para buscar su albergue sea en las grandes casas de inquilinato o en las Ilamadas casas de familia" (Informe municipal citado por Parker, 1995, p. 161). Vivían en entresuelos, habitaciones interiores cerca de corrales pequeños, húmedos, sin ventilación, etcétera.

La incipiente población obrera y la plebe habitaban en casas de vecindad o "casas multifamiliares populares" y los callejones (Calderón, 2000). Las primeras, surgidas en la mitad del siglo diecinueve bajo el impulso empresarial de Enrique Meigs, se ubicaban en el naciente y modesto barrio de La Victoria, o en Barrios Altos. A diferencia del callejón, se trataba de dos pisos unidos por un balcón corrido que

1 En Calderón (2000) se encuentra un tratado de las diversas modalidades de vivienda, por periodos históricos y ampliamente documentado con planos, fotografías y dibujos. 
servía de galería externa, sin servicios de agua potable ni acequias canalizadas. El promotor inmobiliario vendía a precio urbano una tierra rural, en tanto la municipalidad no interpuso acción alguna y pronto las zonas fueron estigmatizadas como barrio de pobres, prostitutas y delincuentes (Torrejón, 2010, p. 76). Los poco ventilados y sucios callejones, que hacia 1903 cobijaban al 25\% de la población (34 498 personas), se ubicaban en el Rímac, con mayor promedio de hacinamiento (Del Águila, 1997, p. 36), Los Barbones (portada de Santa Catalina), Cocharcas, entre los jirones Lampa y Grau y entre los de jirón Puno y Plaza de Guadalupe. También allí vivían los chinos, llegados al Perú entre 1849 y $1874^{2}$. Los callejones proporcionaban a sus dueños renta segura, tratándose de un fundo que "pertenece a algún rico al que poco le importa que el diablo se lleve a los que en él habitan" (Abelardo Gamarra, citado en Ortega, 1986, p. 103).

El primer siglo de la república estuvo dominado por el libre mercado. Las compañías urbanizadoras producían vivienda, en venta o alquiler, para la clase media y alta (La Colmena, Paseo Colón) y los trabajadores (La Victoria). Los promotores inmobiliarios producían tugurios para la plebe bajo el criterio de una inversión lucrativa (Stein, 1986). Solo el 5.7\% de las familias en 1908 vivía en casa propia y la mayoría de artesanos y obreros en viviendas de alquiler. ${ }^{3}$ Entre los tibios límites al mercado se tuvo, en 1908, una ley de expropiación para ensanche y trazado de vías de comunicación promulgada tras un largo debate entre posturas reguladoras y liberales. En el siglo XIX obras de magnitud, como las líneas de ferrocarril, procedían mayormente a través de compras a los propios hacendados (Hidalgo y Jiménez, 2009).

Las preocupaciones higienistas cuantificaron los problemas. Al igual que un siglo antes, la ciudad enfrentó periódicas pestes y epidemias, como las de viruela (1885, 1891-1892, 1902, 1907), sarampión (1885), influenza $(1892,1900)$ y la peste bubónica en 1903-1904 (Torrejón, 2010, p. 70). En 1904 se nombró una comisión para estudiar detalladamente las condiciones sanitarias de las casas de Lima y, hacia 1909, según León García, el "77\% de las personas vivían mal alojadas, el $10 \%$ suficientemente alojadas y el $13 \%$ gozaba con holgura del espacio habitable" (citado en Burga y Flores, 1979, p. 13). Según el censo de 1908, la mitad de los

2 El "barrio chino", entre la actual avenida Abancay y la Plaza Italia, era un conjunto de tugurios y callejones con una densidad de 357 habitantes por hectárea. Entre los 65 callejones se destacaba el de Otaiza, con 109 habitaciones, al costado del mercado central, el cual fue destruido 1909, bajo una política higienista. El acto estuvo precedido por una crisis de empleo y un clima anti chino que incluso había generado motines (Rodríguez, 1995).

3 Debe indicarse que en 1908 se había aprobado una ley de expropiación tras un largo debate entre posturas reguladoras y liberales. En el siglo XIX obras de magnitud, como las líneas de ferrocarril procedían mayormente a través de compras a los propios hacendados (Hidalgo y Jiménez, 2009). 
habitantes de Lima habitaba en callejones y casas de inquilinato, que llegaban a 3465 unidades (Muñoz, 2001, p. 54).

Gradualmente fue surgiendo un incipiente marco regulador a la actividad privada urbanizadora ${ }^{4}$, la cual se alejó un tanto de la política propropietarista predominante. Entre sus causas, la presión social pues tras la conquista por los trabajadores de la jornada de ocho horas (1919), apuntaban ahora a la reproducción solicitando el congelamiento de los alquileres. En cuanto a la demografía, entre 1876 y 1908 unos 50000 habitantes más incrementaron la demanda de vivienda, lo cual hizo subir los costos de construcción y el precio del suelo, el cual tuvo un espectacular incremento por 6 entre 1899 y 1908, aunque se estabilizó entre 1908 y1920, para multiplicarse por dos en 1921 (Torrejón, 2010, p. 89).

Hacia 1915 se buscó controlar, frustradamente, a compañías urbanizadoras que vendían "lotes sin servicios". Una Ordenanza estipuló no dar más licencias para urbanizar hasta que se aprobara el Plan General de Urbanización, prohibiendo construcciones de barrios sin pavimento, instalaciones para alumbrado y servicios de agua y desagüe. En 1919, el Reglamento de Construcciones prohibió construir edificios sobre terrenos pantanosos e inundables, o que hubieran sido depósitos de basuras o cementerios, y definió las características de los cimientos, pisos, techos, sótanos y patios.

\section{Acción reguladora y segregación física (1920-1989)}

En este periodo, que cubre 70 años, se establecieron las bases de la Lima tal como se conoce actualmente. Conviene distinguir dos subperiodos, uno caracterizado por el predominio del mercado inmobiliario y las lógicas de la renta del suelo que establecieron la segregación espacial de las clases sociales; $y$ otro en el cual el Estado, sin afectar mayormente el negocio inmobiliario (salvo el periodo 1968-1976), asumió más funciones reguladoras y de producción de vivienda social, acogiendo al urbanismo y la arquitectura moderna, aunque también oyendo las voces liberales que exigían el supuesto abordaje "realista" de observar a las barriadas como la "solución".

\section{La segregación espacial en la ciudad}

El sistema de vivienda mercantil atendía a los sectores de altos ingresos mediante casas anchas, espaciosas y bien ventiladas, ubicadas en la expansión hacia el sur

4 Ludeña (2014) menciona la aprobación en 1903 de una ley para el saneamiento de las habitaciones obreras. 
y el sur oeste de la ciudad, bajo la batuta de unas 40 compañías urbanizadoras, constituidas entre 1910 y 1925, sobre la base de la concentración de la propiedad agrícola del área de expansión, el desarrollo del sistema financiero y el crédito hipotecario (Calderón, 2016). Quince compañías poseían el 35\% del total del área de expansión urbana de Lima en la década de 1920 (Ísmodes, 2017) y, 30 años después, 11 de los grandes propietarios de tierras controlaban el 52\% de dicha área (Calderón, 2016). Según Hamann (2015), la ciudad contaba hacia 1920 con 1428 hectáreas y hacia 1927 las empresas urbanizadoras llegaron a habilitar hasta 2051.7 hectáreas y en 1930 unas 3000 hectáreas

El mercado inmobiliario privado estableció el actual patrón de segregación espacial de la ciudad (Sánchez León y Calderón, 1980). Las clases altas y media alta se ubicaron en mansiones en Miraflores y San Isidro, en un éxodo que concluiría hacia la década de 1950, bajo el impulso de la obra pública (transporte, pistas, luz y agua) de la década de 1920. En esta expansión se ensayarían nuevos tipos de edificaciones, tal como el modelo chalet (1930-1940) por casi todos los distritos (desde Miraflores al Rímac, pasando por Lince y San Isidro), la casa de campo elegante y las casas estilo buque en Miraflores, Santa Beatriz y La Punta (Calderón, 2000). Las propuestas urbanísticas de Alberto Alexander (citado por Hamann, 2015, p. 164), hacia 1928, en realidad ratificaban las tendencias del mercado al distinguir una"zona residencial" (entre las avenidas Arequipa y Brasil, Pardo y El Ejército), una "zona de atracción" para contar con un plan de formación de bosques y áreas sembradas (entre avenidas Brasil y Venezuela) y la "zona industrial y obrera" (entre Venezuela y el río Rímac), en la cual se debían construir los Barrios Obreros.

Hacia 1931 la ciudad de Lima alcanzaba 332,118 habitantes y un 85\% de la población de Lima vivía en viviendas en alquiler (Calderón, 2015b). La plebe y los obreros seguían habitando tugurios, incorporándose el subtipo del corralón. La tenencia en alquiler de la vivienda, según el censo de 1940, bajó al $81 \%$ y la de propiedad subió del $9 \%$ al $17 \%$. Imperceptiblemente para la época, surgía una nueva modalidad de hábitat popular en la cual se evadía el alquiler: 41 barriadas formadas por invasión o reubicación pública con un peso poblacional insignificante, las cuales pronto cambiarían la faz de la ciudad (Calderón, 2016).

Progresivamente, el Estado empieza a intervenir con normas reguladoras, inversiones públicas (capital fijo) y vivienda social. La actividad reguladora cobró impulso con el gobierno de Leguía (1920-1930), enfrentado a la aristocracia civilista. Entre diversos dispositivos, la ley 4108 de 1920 permitió la expropiación de tierra agrícola para la construcción de obras públicas e infraestructura (Orrego, 2014) y, en 1924, el primer Reglamento de Urbanizaciones para el control de venta de lotes 
fuera del perímetro urbano, adjudicó a la Inspección Técnica de Urbanizaciones y Construcciones, dependiente de la Dirección de Salubridad, la tramitación de urbanizaciones. Este reglamento estableció que un $30 \%$ de la superficie total del suelo a urbanizar debía destinarse a espacios libres (calles, plazas y plazuelas), definió la dimensión de las calles y exigió que toda urbanización debía ceder gratuitamente al Estado un lote igual al $2 \%$ del área total urbanizada, en un plazo improrrogable de 30 días contados desde la fecha de la autorización, ${ }^{5}$ ratificada en el Reglamento de urbanizaciones de 1941. En 1933, un nuevo Reglamento de Construcciones había ratificado la necesidad de licencias, las características de las obras e incluso requisitos para la construcción de callejones y casas colectivas. Por ejemplo, un callejón debía tener habitaciones de cuando menos 12 metros cuadrados, al menos una ducha, un botadero y un excusado por cada 10 habitaciones y los cuartos debían ser de ladrillo.

La acción reguladora fue resistida por las compañías urbanizadoras que siguieron burlando los requisitos de provisión de servicios, surgiendo sucesivos conflictos entre 1924 y 1931 entre urbanizadores, el Estado y los compradores agrupados en el Sindicato de Propietarios y Poseedores de Lotes (Sánchez León y Calderón, 1980). Entre 1926 y 1929, según De Soto (1990), urbanizaciones como Manzanilla, Chacra Colorada o Las Cabezas contravenían las normas, no hacían transferencia del dominio, no proveían servicios. Tras un conflicto con el Estado, en 1931 se produjo una "ley entre las partes", arreglos "por lo bajo".

La modernización de la década de 1920 proveyó un capital fijo (obras, infraestructura) que permitió ganancias a los propietarios de tierras. Se vieron beneficiados, entre 1926 y 1930, con el alza del precio del suelo urbano, el cual pasó de 12 a cerca de 15 soles el metro cuadrado (Ísmodes, 2017). La apertura de la Avenida Arequipa o la instalación de servicios básicos, benefició a los propietarios de tierras vueltos urbanizadores, permitiendo la extracción de plusvalor por medio de la especulación con los derechos de propiedad (Harvey, 1979, p. 328).

En vivienda social existieron antecedentes hacia 1910 cuando la Municipalidad de Lima construyó viviendas sobre un terreno cedido por un particular (Calderón, 2000). El presidente Guillermo Billinghurst, en su mensaje al Congreso de 1913, había declarado: "uno de los problemas que directamente atañen a las colectividades obreras, es el que se refiere a la construcción, con material conveniente, de viviendas sanas, alegres y baratas, para remplazar, cuanto antes, las habitaciones

5 Estos terrenos podían ser destinados a la construcción de edificios públicos (escuelas, comisarías, mercados) y "la edificación de casas baratas para empleados y obreros" (artículos 34, 35 y 36 del Reglamento de Urbanizaciones de 1924, incluido en Ludeña 2004, p. 413). 
insalubres, desprovistas de ventilación" (Mamani, 2015). Entre 1908 y 1919, y luego en la década de 1920, existieron proyectos y obras de viviendas para obreros por la Sociedad de Beneficencia Pública de Lima (SBPL), la Municipalidad de Lima y el gobierno central.

El esfuerzo más significativo se produjo en 1921, aunque no dirigido a la clase trabajadora sino hacia la clase media: la urbanización Santa Beatriz, sobre el fundo del mismo nombre (154 hectáreas), adquirido por el Estado en 1870 tras el derrumbe de las murallas de la ciudad. Hacia 1904, entre otros usos, ya se ubicaba allí la Escuela de Agricultura, el hipódromo, el velódromo, el estadio de fútbol, entre otras amenidades. En 1921, el Congreso autorizó tasar, lotizar y vender la tierra a compañías urbanizadoras para que edifiquen viviendas, exigiendo que los lotes tengan una extensión máxima de 1,500 metros cuadrados, prohibiéndose que algún adquiriente se hiciera de más de un lote y conminándose a las compañías urbanizadoras, por contrato, a edificar en el plazo de 3 años, al cabo del cual la tierra revertiría al Estado. Fue destinada a empleados del Estado, civiles o militares, pretendida base política de Leguía en su enfrentamiento a la aristocracia. Las urbanizadoras adquirían el terreno y edificaban las viviendas a gusto del cliente. Se estima que el promedio del tamaño de los lotes fue menor a lo estipulado, unos 1,200 metros cuadrados.

Hacia 1927, con sus 80 manzanas y 652 lotes, Santa Beatriz concentraba lo mejor de la cosmopolita cultura burguesa, o la mesocracia capitalina, rodeada de un halo de zona de lujo que perduraría hasta la década de 1950 en que atravesó un proceso de "invasión- sucesión". En ciertos casos, la clase media- alta adquirió y construyó para destinarla a la vivienda de alquiler, subdividiendo lotes, lo cual la alejó del ideal de garden city que la animó (Caldas, 2009). En retrospectiva, la experiencia dejó lecciones de urbanismo posteriormente abandonadas. El claro deseo de evitar la especulación con el suelo, destinar el producto de la venta de lotes a reintegrar los fondos de saneamiento tomados por los trabajos de pavimentación y obras de la avenida principal (Flórez Zúñiga, 2015). Con la venta de la tierra el Estado cubría el costo de la infraestructura y, de una inversión de 2 millones de soles, el gobierno obtuvo por la venta de lotes casi 4 millones de soles (Orrego, 2014).

En la década de 1930 se construyeron Barrios Obreros, quintas y Barrios Fiscales, a través de la Sociedad de Beneficencia Pública de Lima (SBPL) y la Junta Departamental Pro Desocupados de Lima del Ministerio de Fomento y Obras Públicas (MFOP). Esta Junta había surgido como respuesta a los efectos de la crisis económica de 1930, y la ley 7571 , de 1932, destinó el $20 \%$ del impuesto pro desocupados a la reconstrucción de inmuebles de la SBPL, la cual contaba con un stock de terrenos para renovación urbana. La SBPL entre 1932 y 1941 construyó quintas o casas para 
obreros, adoptándose las primeras formas de la arquitectura modernista (Maldonado y Torre, 2010). Una vivienda obrera fue definida en 1936 (Ley 8487) como aquella con un alquiler hasta 50 soles. Se hicieron 36 proyectos de vivienda, de los cuales 27 fueron dirigidos para obreros, edificándose en total 518 casas sobre 17 hectáreas. ${ }^{6}$ Esta labor fue interrumpida en 1942, cuando el Gobierno de Manuel Prado (1939-1945) cortó el financiamiento establecido por los aportes de la Ley 7571 (Jiménez y Santibáñez, 1994).

\section{Urbanismo moderno y barriada}

El periodo 1945-1989 coincide, a grandes rasgos, con la Industrialización por Sustitución de Importaciones (ISI) que, bajo un proyecto desarrollador y modernizador, buscaba cambiar una estructura económica primario extractiva por otra industrial, en la ruta seguida por los entonces países industrializados. En ese camino, como corresponde a un patrón repetitivo, se engarzan los esfuerzos frustrados del urbanismo moderno por generar ciudades diferentes y una política de vivienda social orientada a una ciudad moderna y racional.

El urbanismo moderno recibió el impulso del gobierno de Bustamante y Rivero (1946-1948), quien dispuso la congelación de alquileres en viviendas privadas y públicas. Se creó en 1946 la Corporación Nacional de la Vivienda (CNV), adscrita al Ministerio de Fomento y Obras Públicas (Ley 10359), iniciándose la construcción de las Unidades Vecinales, entregadas en alquiler. La CNV era una empresa pública de derecho privado que podía formular planes, construir y reconstruir viviendas, firmar contratos, ejecutar obras de urbanización, administrar los Barrios Fiscales y Municipales, alquilar, conceder préstamos hipotecarios, adquirir bienes inmuebles, entre otros. Fue dotada de un aporte de 100 millones de soles, así como activos en terrenos de propiedad del Estado.

El gobierno del general Manuel Odría (1948-1956), instalado en el poder mediante un golpe de Estado decidido a "restaurar" el orden con apoyo de los grupos de poder, continuó la labor de vivienda social. Entre 1952 y 1955 destinó para vivienda construida unos 172 millones de soles, el 42.5\% de una inversión total de 404 millones de soles (Candela et al., 2017). Adquirió fundos para ejecutar unidades vecinales como las de Matute, Rímac y La Corporación de El Agustino, extendió los programas de vivienda hacia Arequipa $(1948,1956)$ y Cusco $(1950$,

6 La información de Ludeña, sobre un periodo más amplio, indica que se construyeron 132 lotes en quintas, entre 1911 y 1927, y unas 3333 casas de obreros y viviendas en barrio obreros entre 1925 y 1942 (Ludeña, 2004). 
1953, 1954). Aunque, por sus costos, el gobierno de Odría pronto advirtió que la vivienda social no llegaba a los realmente pobres, tal como pensaban los urbanistas modernos. Empezó, entonces, un apoyo sistemático a la formación de barriadas, una solución más barata y que a través de prácticas de clientelismo lo legitimaba. Entre 1948 y 1956 se formaron 81 barriadas, a 10 por año (Calderón, 2016, p. 140), siendo la más emblemática la "Urbanización Perú", hoy zona histórica del distrito de San Martín de Porres.

En la mano derecha Odría atendió los intereses de los grupos urbanizadores. El Reglamento de Urbanizaciones y Subdivisión de Tierras (D.S. 01- F del 20 de enero de 1955) eximió a las compañías urbanizadoras de la cesión del $2 \%$ de sus tierras establecido desde 1924, permitió la parcelación semirústica, un modo de urbanizar sin contar con los requisitos previos, y creó las "Urbanizaciones Tipo Popular", estableciendo que, en virtud de la ley 10272, el Estado podría aportar "terrenos fiscales o eriazos" (Cabello, 2006). En 1951, el Código de Minería había permitido que los concesionarios mineros (los mismos grupos de poder) urbanizaran luego en su provecho la tierra pública, lo cual permitió la apropiación de suelo en el distrito de La Molina, en el que el grupo Aparicio y Figari recibiría en 1961 en la Planicie de Pampa Grande 1910 hectáreas y otras 170 hectáreas de una arenera, las que empiezan a habilitar a partir de 1961 para la clase alta (Orrego, 2012).?

Hacia mediados de la década de 1950 se incrementaron las demandas liberales respecto a que el Estado abandone la producción de vivienda social, así como las misiones norteamericanas que arribaban al país para promover la autoconstrucción, ${ }^{8}$ por lo cual se había encargado a la CNV desarrollar tipologías de vivienda de "urbanización popular" (Kahatt, 2015). Finalmente, las intenciones liberales se plasmarían con el segundo gobierno de Manuel Prado (1956-1962). Se abandonó las ilusiones del urbanismo moderno por vivienda pública construida, bajo el argumento que dicha labor no le correspondía al Estado, sino al mercado; se favoreció a los grupos urbanizadores al servicio de las clases medias sosteniendo que el Estado debía aportar infraestructura (capital fijo) y promover el sistema mutual (1957), un subsidio "a la oferta" importado de la experiencia norteamericana.

Para los pobres, se legalizó las invasiones a través de la ley de barriadas de 1961 que creó las Urbanizaciones Populares de Interés Social (UPIS), una modalidad de

7 En 1955 amigos del gobernante, incluyendo a urbanizadores y constructores, le obsequiaron el "Fundo Odría" ( 6 hectáreas), en la exclusiva zona de Monterrico, y cuya denuncia fue desestimada por el Congreso en 1957 (Quiroz, 2013).

8 El gobierno de Estados Unidos impulsaba la autoconstrucción desde 1948, a partir de un proyecto piloto en Puerto Rico y, hacia 1954, misiones norteamericanas impulsaban modalidades alternativas a la vivienda construida (la "casa que crece"). 
lotes con servicios en la periferia. Las UPIS obtuvieron apoyo de la Alianza para el Progreso, la cooperación norteamericana y el Banco Interamericano de Desarrollo (BID). Entre sus expresiones la Ciudad Satélite de Ventanilla sobre tierra pública, a $20 \mathrm{~km}$ del centro, y un Programa de Lotes y Servicios para 40841 familias en 25 ciudades, unas 16000 familias en la ciudad de Lima, a un costo de lote de 298.2 USD de la época (Harris y Hossé, 1963, p. 260). Mientras tanto, entre 1956-1960 se habían formado 76 barriadas en Lima, a razón de 19 por año.

Entre 1950-1960, la estructura urbana de Lima pasó de metrópolis a megalópolis, aunque reproduciendo el patrón de segregación espacial iniciado hacia la década de 1920: la clase media y alta en el área central y los sectores de menores ingresos en la periferia (los llamados "conos" sur, norte y este). La población en barriada, desplazó al tugurio como modelo de vivienda popular, creció de 316426 en 1961 (17\%) a 2188415 en 1993, constituyendo el 38\% de la población (Calderón, 2016, p. 246).

Hacia la década de 1960 se inician esfuerzos públicos por controlar la especulación con el suelo por parte de los grupos urbanizadores (Junta Militar de Gobierno 1962-1963 y gobierno de Velasco 1968-1975). En el intermedio, se produjo un breve retorno al urbanismo moderno con el gobierno de Fernando Belaunde (1963-1968), las segundas etapas de la Unidades Vecinales, los Conjuntos Habitacionales (San Felipe, Santa (ruz) y el abandono de los programas de lotes y servicios. Belaunde pensaba que la solución a la habitación de los pobres era la vivienda social en altura, a pesar de ser inalcanzable para ellos, dejando de lado la aplicación de la ley de barriadas, entregando pocos títulos de propiedad, y abandonando las UPIS y los planes de adquirir tierra en la periferia. ${ }^{9}$ En la medida que los proyectos fueron abandonados, sus expectantes beneficiarios los invadieron (Calderón, 2016).

La JMG 1962-1963, a pesar de su breve mandato incorporó la gestión del suelo a la política de vivienda, expidiendo en 1962 el D. L. 14197 que definió la propiedad pública de los arenales que rodeaban las ciudades costeras, frenando su apropiación por los grandes grupos urbanizadores vía las concesiones mineras. Flexibilizó el mecanismo de expropiación de tierras (D. L. 14931 de 1963), reduciendo el monto del pago inicial (al 8\%) y simplificando los procedimientos de la Constitución de 1933, el Código Civil de 1936 y la Ley de Expropiación Forzosa 9125 de 1941 (Calderón, 2016). El gobierno del general Juan Velasco (1968-1975) dio más pasos convirtiéndose en promotor de los asentamientos precarios, a los que bautizó como

9 Con financiamiento del BID se concluyeron algunos proyectos. En Lima, según Kahatt (2015), se tuvo San Juan (8,000 lotes), Conde Villa-Señor (4411 lotes), Pamplona (1676 lotes), Collique (2655 lotes), Caja de Agua (1207 lotes) y Tahuantinsuyo (3868 lotes). Se ha estimado que comprendían unas 524 hectáreas, 15667 lotes al servicio de 77834 habitantes (Calderón, 2016). 
"Pueblos Jóvenes" (Calderón, 2016), aunque no abandonó totalmente la vivienda construida (Los Próceres, Los Precursores) y efectuó algo de renovación urbana (EI Porvenir, PREVI Barranco, Manzanilla, Tarapacá).

El gobierno de Velasco creó el Ministerio de Vivienda (1969) y estableció políticas de gestión del suelo, antes ausentes, entre ellas la Ley de Reforma Agraria de 1969 $\left(N^{\circ} 17716\right)$, la cual golpeó a los grupos urbanizadores estableciendo una extensión inafectable con un máximo de 15 hectáreas y un plazo de habilitación urbana de cinco años, al cabo del cual revertirían al dominio estatal. El D. L. 17803, de 1969, estableció la expropiación forzosa para ensanche de poblaciones beneficiando a barriadas hacinadas que requerían terrenos para reubicar a los excedentes. Se apeló al artículo 34 de la Constitución de 1933 que indicaba que la propiedad debía usarse en armonía con el interés social y que la ley debería fijar los límites y modalidades del derecho de propiedad. ${ }^{10}$ En 1972, el D. L. 19955 determinó como sujeto de expropiación los terrenos no productivos y, en 1973, el Estado recuperó 1500 hectáreas de un grupo urbanizador, iniciándose un juicio que aún continúa y en la que el gobierno creó la UPIS Huáscar. En 1977 se estableció un impuesto a los terrenos sin construir (Calderón, 2016).

La política pública de gestión del suelo extinguió a los grupos urbanizadores, que habían orientado la expansión de la ciudad por décadas, al despojarles de su principal mecanismo de acumulación: la capacidad de retener y especular con las tierras. Paradójicamente, la contra respuesta de los urbanizadores fue abrir un submercado ilegal de lotizaciones a través de asociaciones o cooperativas de vivienda para burlar la reforma agraria (el cual floreció en distritos como Ate, San Martín de Porres, El Agustino). Por otro lado, al afirmar la formación de barriadas por reubicación sobre tierra pública (Villa El Salvador en 1971, Huáscar Canto Grande en 1976, Huaycán en 1984 y Mi Perú en 1987) confirmó y consolidó la tendencia segregadora a ubicar a los "pobres" en periferias lejanas, a unos 20 kilómetros de la ciudad.

Posteriormente, los mecanismos de gestión del suelo (el impuesto a los terrenos sin construir en 1977 y la defensa de las áreas agrícolas hacia 1985) fueron abandonándose hasta ser eliminados en la década de 1990. Las políticas de vivienda recurriendo al Fondo Nacional de la Vivienda (1979), una contribución del capital y del trabajo, impulsaron conjuntos habitacionales (Torres de San Borja y Limatambo, Santa Rosa), ${ }^{11}$ y afirmaron el apoyo a las barriadas a través de programas

10 El DL 17803 fue derogado por el decreto legislativo 313 de noviembre de 1984 expedido por el segundo gobierno de Belaunde (1980-1985).

11 Belaunde recurrió a terrenos públicos o en litigio, consecuencia de los enfrentamientos a que dio lugar la aplicación de la reforma agraria en la década de 1970. El caso más notorio fue el del programa Las Torres de 
de lotes con servicios y el Banco de Materiales (BANMAT), creado en 1981. Con el primer gobierno de Alan García (1985-1990), el FONAVI se desvirtuó usándose para proveer servicios básicos a las barriadas, antes que vivienda construida, y su mayor obra fueron los créditos del BANMAT (40\%). La Municipalidad de Lima (1984-1986) tuvo intervenciones en tres ámbitos: la defensa del medio ambiente declarando la intangibilidad agrícola de tierras de expansión en manos de pequeños propietarios beneficiarios de la reforma agraria, modificando el sistema tributario municipal incorporando el instrumento de Contribución de Mejoras y desarrollando programas ordenados de acceso al suelo (Huaycán).

Entre la década de 1920 y la de 1980 en Lima los grupos urbanizadores desaparecieron, aunque permaneció el patrón de segregación social y espacial que el mercado había establecido. La clase alta y media en el área central (a la cual se había incorporado la expansión Sur-Este con Surco, San Borja y La Molina). Los pobres en los tugurios céntricos en franco descenso. Estos habían pasado de cobijar a 298900 habitantes en 1955 a 572232 en 1961 (31\% de la población), para descender a 488648 habitantes en 1967 y a 393630 en 1981 (8.5\%) (Calderón, 2016, pp. 133-134). En cambio, la barriada creció en proporción inversa, pasando de 119000 pobladores (10\%) en 1961, a 1329600 (29\%) en 1981 y a 2188415 habitantes (34.4\%) en 1993. Si Lima Metropolitana creció en promedio entre 1972 y 1981 a tasa de 3.2, San Juan de Lurigancho lo hizo a tasa de 12.9 y Ate a 10.1. Entre 1981-1983, la ciudad creció a una tasa de 2.7, pero Ventanilla lo hizo a 14.2 y Puente Piedra a 10.7 (INEI, 1997, p. 317). Con los años, los pobres y las barriadas se asentaban cada vez más lejos de las centralidades, pasando luego a constituir "distritos populares".

Resulta difícil establecer un balance de la edificación de vivienda pública entre 1930-1999. A partir de diversas fuentes, como Ludeña (2004) para el periodo 19301970 y Dongo (2009) para 1980-1999, sobre la base de información del Ministerio de Vivienda y Construcción, el Estado edificó unas 81460 viviendas, a razón de 1180 por año. Entre 1930 y 1960, predominaron Barrios Obreros o Fiscales, Unidades Vecinales, Agrupamientos y Conjunto Habitacionales edificándose unas 43172 unidades de vivienda. En la década de 1970 se construyen 23313 unidades, número que debe sorprender por el mito que Velasco "abandonó la vivienda construida" y, posteriormente, el segundo belaundismo (1980-1985) construyó 22937 unidades hasta que la obra en vivienda se restringe, mayormente, a los préstamos del Banco de Materiales, los cuales no pueden ser considerados como unidades construidas (ver gráfico 1).

San Borja en un terreno de propiedad de la familia Marsano, cuyo juicio e indemnización se resolverían el siglo XXI. 
Frente a esta vivienda formal, las barriadas, con unos 1329600 habitantes en 1981 aportaron un stock de 265920 viviendas y, hacia 1993, unos 858815 pobladores más unas 171763 viviendas más. En esta contabilidad, se incluyen lotes con servicios y lotes tizados, eufemismo que incluye a las barriadas reubicadas (como Villa El Salvador). A un cálculo razonable, las barriadas habían aportado 437683 viviendas frente a poco más de 81000 viviendas públicas, más de 5 veces más, sin considerar en este estimado la vivienda producida por la empresa privada.

\section{Gráfico 1. La obra en vivienda}

\section{Obra en vivienda 1940-2000}

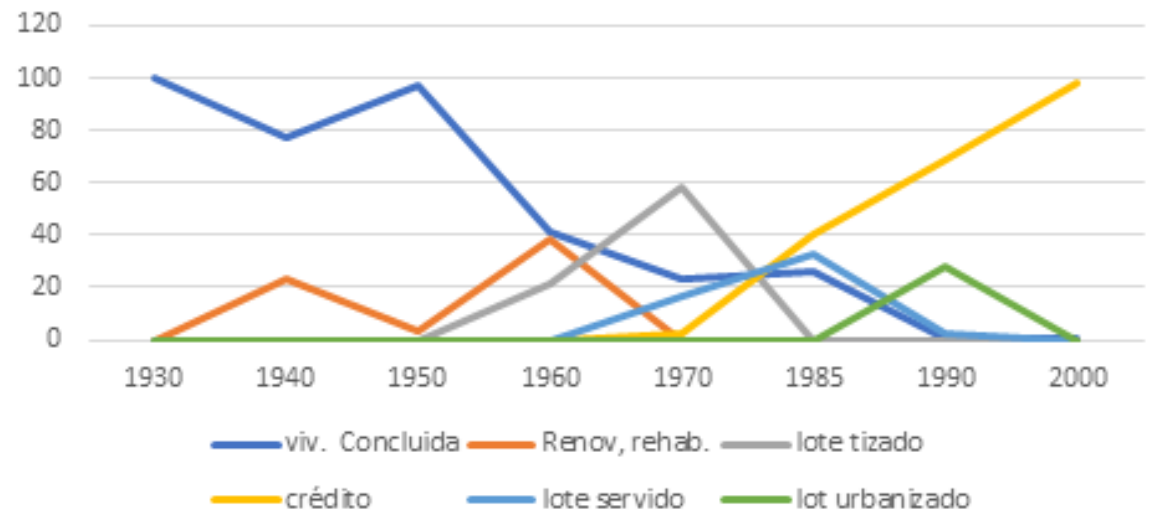

Fuente: MVCS.

\section{El reino del mercado (1990-2020)}

Cuando hacia 1990 el Perú ingresa a la onda neoliberal (desindustrialización, desregulación, flexibilidad laboral, privatizaciones), el Estado se volvió, antes que regulador, facilitador de la inversión privada. En esta ocasión, la solución fue importada desde el Banco Mundial el cual, en el ámbito de la vivienda, buscaban permitir que los mercados habitacionales funcionaran de forma más eficiente, en el marco de la suspensión de los apoyos de las agencias públicas (Banco Mundial Housing: Enabling Markets to Work, citado por Rolnik, 2017, p. 67). El Banco Mundial recomendaba a los gobiernos abandonar su antiguo papel de productores de vivienda y asumir un papel facilitador en la gestión habitacional.

Los gobiernos neoliberales en el Perú (1990 y 2020), auspiciaron un Estado"facilitador" que dejó las "soluciones" de vivienda en manos del mercado. Esto podría 
sonar a contrasentido cuando resulta claro que, en Lima, la estructura urbana en forma de triángulo de Isósceles bajo un patrón de segregación de las clases sociales, había sido labrada a pulso desde la década de 1920 por el mercado.

Correspondió al gobierno de Alberto Fujimori (1990-2000), democrático primero y dictatorial luego, una serie de (contra) reformas institucionales que combinaron un liberalismo a ultranza con populismo. Entre las medidas más saltantes, la supresión de la política de vivienda, empezando por desaparecer en 1992 al Ministerio de Vivienda, algo que ni siquiera el modelo chileno experimentó. Desaparecieron todas las instituciones financieras (Banco de la Vivienda y sistema mutual) y la acción destructiva creadora modificó los instrumentos de gestión del suelo creados entre 1963 y 1985. En 1993 la nueva constitución eliminó el derecho a la vivienda y prohibió la intervención económica del Estado, se recortó el alcance de la ley de expropiación (eliminación de la causal de función social) y una reforma tributaria municipal eliminó la Contribución de Mejoras y los impuestos a los terrenos sin construir. Se liberaron "obstáculos" a los propietarios de tierras a través de la Ley de Tierras (1995), la cual levantó las intangibilidades agrícolas, y la autorización a las comunidades campesinas de la costa, en 1997, a vender sus tierras, desechando una protección que venía desde la década de 1920.

Hacia los pobres el Estado dejó de promover programas de acceso ordenado al suelo, auspició políticas individualistas y de promoción de la propiedad privada a través de la titulación masiva de tierras ocupadas informalmente y aplicó el laissez faire a las barriadas, por lo cual Lima pasó de 1147 asentamientos en 1993 a 3653 en 2002 (Calderón, 2006). Se ocuparon, a veces con auspicio clientelar, todo tipo de terrenos (áreas de riesgo, pantanos, cerros, quebradas), espacios residuales de la ciudad, cuyo efecto en la calidad de vida y mente de sus habitantes es todavía una deuda de las ciencias sociales. Al punto que esta realidad es mejor conocida desde la ficción, a través de películas como Paraíso (2009) de Héctor Gálvez y Alienación (2020) de Alex Fishman, documentos realistas frente a los estudios urbanos.

Una política de vivienda construida se esbozó hacia 1997 y 1998 con la creación del Fondo Mi Vivienda (FMV), bajo presión de la Cámara Peruana de la Construcción (CAPECO), y tomó forma en el 2002 con la creación del Ministerio de Vivienda. ${ }^{12}$ La política favoreció a la clase media a través del FMV, luego llamado Nuevo Crédito Mivivienda (MCMV), y frente a los sectores de menores ingresos se

12 Desde el 2002 se crearon el Bono Familiar Habitacional (ley 27829 del 20/09/02), el Programa Techo Propio R.M. 054-2002- VIVIENDA, el Reglamento Nacional de Edificaciones (D.S. 015-2004-VIVIENDA y R. M. 290-2005-VIVIENDA DEL 26/11/05), el Plan Nacional de Vivienda 2006-2015 y en el 2007 la Ley 29090 de Regulación de Habilitaciones Urbanas y Edificaciones. 
creó el programa Techo Propio (D.S. 054-2002) en tres modalidades: Vivienda Nueva (AVN), Construcción en Sitio Propio (CSP) y Mejoramiento de Vivienda. Mientras la primera construía nuevas viviendas, las dos últimas se dirigían a pobladores de asentamientos precarios, al igual que las políticas de regularización/ titulación de la tierra, mejoramiento en servicios básicos y apoyo a los autoconstructores (Banco de Materiales).

El periodo (neo) liberal ha resultado monocorde, con pocos y leves cambios. En sus inicios, la política orientada hacia la clase media tuvo gran éxito porque acompañó el incremento de estos grupos sociales y el proceso de diferenciación social generado por las reformas económicas de la década de 1990 (Calderón, 2009). Tuvo un comportamiento irregular con un pico hacia los años 2005, 2012 y 2013, distinguiéndose en sus productos los "macroproyectos" (grandes unidades habitacionales, tipo Parques de El Agustino o Sol de Collique) y los edificios incrustados desordenadamente en la malla urbana.

Tabla 1. Obra en vivienda entre 1999-2017

\begin{tabular}{|c|c|c|c|c|}
\hline Años & AVN & CSP & MV & FMV \\
\hline 1999 & & & & 143 \\
\hline 2000 & & & & 405 \\
\hline 2001 & & & & 1442 \\
\hline 2002 & & & & 3611 \\
\hline 2003 & 3709 & & & 6166 \\
\hline 2004 & 1992 & 27 & & 7960 \\
\hline 2005 & 702 & 32 & & 9205 \\
\hline 2006 & 625 & 15 & 9 & 5540 \\
\hline 2007 & 2262 & 762 & 163 & 3123 \\
\hline 2008 & 2077 & 10029 & 922 & 2994 \\
\hline 2009 & 4085 & 22807 & 1753 & 3527 \\
\hline 2010 & 5144 & 12807 & 543 & 6436 \\
\hline 2011 & 6014 & 6062 & 388 & 8888 \\
\hline 2012 & 4498 & 12957 & 405 & 10133 \\
\hline 2013 & 3414 & 20493 & 8 & 12064 \\
\hline 2014 & 4260 & 40878 & - & 10226 \\
\hline 2015 & 2836 & 46467 & 1101 & 8227 \\
\hline 2016 & 1576 & 34344 & 2925 & 7872 \\
\hline \multirow[t]{2}{*}{2017} & 3182 & 20421 & 1776 & 4938 \\
\hline & 7594 & 101232 & 5802 & 21037 \\
\hline
\end{tabular}

Elaboración: Julio Calderón

Fuente: Página web del MVCS. 
A los sectores de menores ingresos no les fue tan bien. Techo Propio, Vivienda Nueva (AVN) nunca alcanzó su meta anual de 10000 unidades, y su cima fue el año 2011 con 6000 unidades. En cambio, CSP, gracias a un cálculo adecuado entre el monto del subsidio y el costo de la vivienda, desarrolló un negocio rentable, tan auspicioso que los gobiernos en dos oportunidades (2009 y 2017) lo frenaron por su alto monto de subsidio (un $90 \%$ aproximadamente) bajo el argumento que"no se podía regalar viviendas a la gente". Actualmente, CSP recibe mayor financiamiento, produce más unidades e incluso la gran empresa privada muestra interés (ver tabla 1).

El éxito o fracaso de la política de vivienda depende del ajuste del desarrollador entre el valor de la vivienda social, el monto del bono familiar habitacional y el costo del suelo. El suelo, dejado al juego de la oferta y la demanda como consecuencia de las reformas liberalizadoras de 1990, dio paso a la puja entre promotores inmobiliarios y propietarios del suelo, constituyendo la espada de Damocles para Techo Propio, modalidad AVN. Los desarrolladores no podían comprar suelo para los emprendimientos a un precio menor a 50 dólares el metro cuadrado, y este se elevaba por una mayor demanda representada por un programa público destinado a la clase media (FMV o NCMV) y el boom de la construcción, el cual multiplicó por 7 el precio del suelo entre 2006 y 2012 (Calderón, 2015).

Los grupos de poder no han querido retomar o adoptar nuevas medidas de gestión del suelo, a diferencia de lo que ocurren en países vecinos como Brasil o Colombia. Las medidas no han pasado de solicitar a la Municipalidad de Lima cambios en la zonificación (de uso industrial a residencial), o de entregar tierras públicas por debajo del precio del mercado (ex cuarteles militares o aeródromos). Hacia el 2006, el BID, vía el Programa de Apoyo al Sector Habitacional (PASH), creó el componente de Producción Urbana Primaria (PUP) para proveer suelo, un fracaso total sin que las razones hayan sido expuestas públicamente. Con Humala (2011-2016), se creó el Programa de Generación de Suelo Urbano (PGSU) que volvió a fracasar, aunque ahora porque carecía de un manejo empresarial y, entonces, se empezó a hablar, en el 2015, de la necesidad que el Estado tenga un Operador Urbano (Banco Mundial), un asunto aun no materializado.

El crecimiento de Lima entre 1990-2020, sobre una estructura urbana configurada con anterioridad, observa un sistema de vivienda con un mercado privado excluyente, el cual incluye la generación de condominios cerrados o clubes de campo, y que margina a la mayoría de la población, "demanda no solvente". Una política público-privada que defiende la rentabilidad privada y que ha fallado en sus metas y en la reducción del déficit (sólo 11\% de la demanda cuantitativa), en tanto que la informalidad urbana se ha incrementado a través de submercados ilegales 
(y delictivos) de lotizaciones y"cuartos" de alquiler en zonas barriales consolidadas. Entre 1993 y 2012 las barriadas pasaron de 1147 a 4453 en Lima y la población en barriadas se incrementó en 3168983 habitantes, lo cual, a razón de 4 personas, equivaldría a 792245 viviendas en periferias alejadas y en la miseria (tabla 2).

Tabla 2. Barrios urbano Marginales en 1993, 2002 y 2012

\begin{tabular}{|l|l|l|l|}
\hline & 1993 & 2002 & 2012 \\
\hline $\begin{array}{l}\text { BUM en nivel } \\
\text { nacional }\end{array}$ & 2.998 & 7.419 & 8.94 \\
\hline BUM en Lima & 1.147 & 2.705 & 4.453 \\
\hline $\begin{array}{l}\text { Población de } \\
\text { BUM nacional }\end{array}$ & $4,473,675$ & $7,717,336$ & $7,642,658$ \\
\hline $\begin{array}{l}\text { Población de } \\
\text { BUM en Lima }\end{array}$ & $2,188,415$ & $2,072,245$ & $4,105,884$ \\
\hline
\end{tabular}

Fuente: MVCS.

Los efectos de la política de vivienda han sido contrarios a los deseos de los policy makers y los organismos multilaterales y sus expertos. Siendo impensable que el propósito haya sido estimular la informalidad, pese al atractivo que el clientelismo genera, hay una contradicción entre la propuesta de política y sus resultados, entre los modelos ideales de libre mercado y el comportamiento y rentabilidad de los agentes individuales. Por ejemplo, la Ley de Tierras (1995) levantó la intangibilidad de tierras agrícolas esperando la gran inversión privada para promover mercados formales de tierras y elevar la oferta ( $\mathrm{y}$ bajar los precios, como reza el credo). Pero, en realidad, promotores inmobiliarios informales adquirieron la tierra a los pequeños propietarios agricultores. Algo similar puede decirse de las reformas a las tierras de las comunidades campesinas de la costa. Se ha otorgado 2. 5 millones de títulos de propiedad a ocupantes informales entre 1996-2017, pero aún restaban 2.3 millones de predios por regularizar en las ciudades por el laissez faire a la barriada (MVCS, 2018).

\section{Conclusión}

En 200 años de república la ciudad de Lima ha pasado de 64 mil a 10 millones de habitantes, y por cinco procesos de modernización (1850, 1890, 1920, 1950 y 1990), el último de los cuales traía la buena nueva que el desarrollo podía alcanzarse sin industrializarse, a diferencia del camino que hoy emprenden los países que precisa- 
mente se desarrollan (Corea, China). La vida en la ciudad continúa encerrada en el círculo de miseria que la ha caracterizado, y su crecimiento espacial (el cual sobrepasa las 200000 hectáreas), cual mancha de aceite, se ha extendido por fronteras sin límites, ocupando todo tipo de suelo en periferias alejadas, incluyendo áreas de riesgo, desprovistas de servicios básicos y vías de comunicación. El sistema de vivienda dirigido por el mercado, con escasa regulación pública, ha generado una expansión fragmentada, constituida por un crecimiento vertical en el área central y una expansión horizontal "de lujo" hacia el sur, y por los pobres arrojados hacia las periferias de tierra pública sin servicios públicos y bajo mecanismos informales.

El proceso de desigualdad social se expresa en las oportunidades dispares que se ofrecen a las clases sociales. Las mayorías, ubicadas en el espacio, deben atravesar décadas sin condiciones decentes hasta que gradualmente habiliten. El paso del predominio del tugurio a la barriada, si bien ha brindado más espacio, ha perjudicado la geografía de oportunidades de los pobres quienes tienen que movilizarse por largas distancias cotidianamente, sin infraestructura adecuada y con centralidades de empleo ubicadas en el área central. A la desigualdad en las condiciones materiales de vida, en la dimensión simbólica se añade el estigma y la exclusión (cierre social) hacia los sectores populares bajo relaciones de jerarquía y distanciamiento. El patrón de segregación espacial de las clases sociales se ha ampliado.

La vivienda no ha constituido para las elites gobernantes un derecho social. En 200 años sólo existió constitucionalmente un supuesto "derecho a la vivienda" durante 14 años (de 1979 a 1993), y el problema habitacional no ha dado lugar a políticas de suelo ni de mecanismos explícitos de gestión de la tierra urbana (salvo un corto periodo en 1970), bajo la ilusión liberal que el asunto sería resuelto por los mecanismos del mercado. Los escasos esfuerzos reguladores enfrentaron la oposición de las elites dominantes, desde la oposición a la regulación en la década de 1920 hasta la desregulación total desde 1990. Una paradoja en un país con, probablemente, la mayor cantidad de tierra pública en América Latina. La oportunidad que brinda un suelo que representa un tercio del costo de una vivienda, no ha sido aprovechada para asegurar una vivienda decente a vastos sectores de la población.

\section{Bibliografía}

BURGA, M. y A. FLORES GALINDO (1981). Apogeo y crisis de la república aristocrática. Lima: ediciones Rikchay Perú.

CABELLO, L. (2006). Urbanismo estatal en Lima Metropolitana. Las urbanizaciones populares (1955-1990). En Ur[b]es. Vol. 3, Lima, enero- diciembre, pp. 83-110. 
CALDAS, P. (2009). "Variantes pintorescas del estilo inglés limeño en la vivienda de Santa Beatriz, 1920-30". En Ciudad y Arquitectura Vol. 2, N| 1. Lima: UNI.

CALDERÓN, G. (2000). La casa limeña. Espacios habitados. Lima: Siklos, S.R. Ltda.

CALDERÓN, J. (2016). La ciudad ilegal. Lima en el siglo XX. Lima: Punto Cardinal.

CALDERÓn, J. (2015). "Programas de vivienda social nueva y mercados de suelo urbano en el Perú". EURE 41(122), 27-48.

CALDERÓN, J. (2015b). Hacia una vivienda pública en alquiler en el Perú. Mercado de alquileres y Estado". En Wasi. Revista de estudios sobre vivienda, Vol. 2, №3.

CALDERÓN, J. (2009). El efecto Mivivienda: política de vivienda para la clase media y diferenciación social. Ecuador Debate, número 76, abril pp. 107-122

CALDERÓN, J. (2006). Mercado de tierras urbanas, propiedad y pobreza. Lima: LILP-Sincos. CAndela, E, F. Contreras y J. Lossio (2017). “Populismo y salud pública durante el ochenio de Odría (1948-1956). En Acta Herediana, vol 60, abril septiembre.

ClaPHAM, D. (2012) ."Social Policy Approaches to Housing Research". En Clapham, D, W. Clark and K. Gibb Housing Studies. Los Angeles: Sage.

DE SOTO, H. (1990). El otro sendero. Lima: ILD.

DEL ÁGUILA, A. (1997). Callejones y mansiones. Espacios de opinión pública y redes sociales y políticas en la Lima del 900. Lima: PUCP.

DONGO, C. (2008). “De la desinstitucionalización a la legitimación de la vivienda”, Lima: UNI monografía de maestría.

FloRES Galindo, A. (1984). Aristocracia y plebe. Lima, 1760-1830. Lima: Mosca azul editores. FLORES-ZúNIIGA, F. (2015). Haciendas y pueblos de Lima. Historia del valle del Rímac. Lima: Fondo Editorial del Congreso- MML.

HAMANN, J. (2015). Leguía, el Centenario y sus monumentos. Lima: 1919-1930. Lima: PUCP HARVEY, D. (1979). Urbanismo y desigualdad social. México: siglo XXI.

HARRIS, W y H. Hossé (1963). La vivienda en el Perú. Washington D.C.: Unión Panamericana. HIDALGO, N. y C. JIMÉNEZ (2009). Los tranvías de Lima 1878-1965. Lima: Cope Copi.

ÍSMODES, J. (2017). Aspectos históricos del desarrollo urbano de Lima y el rol de sus agentes económicos, 1880-1930. Tesis para obtener el grado de doctor en ciencias sociales por la UNMSM, Lima.

JimÉNEZ, L. y M. SANTIBAÑEZ (1994). Rafael Marquina. Arquitecto. Lima: Tesis Universidad Nacional de Ingeniería (UNI).

KAHATT, S. (2015). Utopías construidas. Las Unidades Vecinales de Lima. Lima: PUCP. LUDEÑA, W. (2004). Lima Historia y Urbanismo en Cifras 1821-1970. Lima: MVCS- UNI. LUDEÑA, W. (2014). “Crisis urbana, el discurso higienista y el problema de la vivienda en Lima de 1900". En Wasi. Revista de estudios sobre vivienda, Vol. 1, № 2. 
Maldonado H. y J. ToRRE (2010). "Los barrios obreros de la Junta Pro desocupados: nuevas formas de plantear lo urbano en la Lima de los 30". En Investigaciones Sociales Vol. 14 $\mathrm{N}^{\circ}$ 24, 189-208, Lima: UNMSM.

MAMANI, Y. (2015). Primeras viviendas obreras en Lima 1909-1911. Seminario de Vivienda de Interés Social, Lima: FAUA-UNI.

MUÑOZ, F. (2001). Diversiones públicas en Lima 1890-1920. La experiencia de la modernidad. Lima: Red para el desarrollo de las Ciencias Sociales.

MVCS, Ministerio de Vivienda, Construcción y Saneamiento (2018). Plan Nacional de Vivienda 2018-2030. Borrador. Lima: MVCS.

ORREGO, J. (2014). ¡Y llegó el centenarioj. Lima: Titanium.

ORREGO, J. (2012). El distrito de La Molina. En blog pucp.edu.pe/blog/juanluisorrego

PARKER, D. (1995). Los pobres de la clase media: estilo de vida, consumo e identidad en una ciudad tradicional. En Panfichi, A. y F. Portocarrero Mundos interiores: Lima 18501950. Lima: CIUP,

QUIROZ, A. (2013). Historia de la corrupción en el Perú. Lima: IEP-IDL.

Rodríguez H. (1995). La calle del Capón, el callejón Otaiza y el Barrio Chino. Pp. 397-430. En Panfichi, A. y F. Portocarrero Mundos interiores: Lima 1850-1950. Lima: CIUP,

ROLNIK, R. (2017). La guerra de los lugares. La colonización de la tierra y la vivienda en la era de las finanzas. Santiago: LOM.

SÁNCHEZ LEÓN, A. y J. CALDERÓN (1980). El laberinto de la ciudad. Políticas urbanas del Estado 1950-1979. Lima: Desco.

STEIN, S. (1986). Lima obrera 1900-1930. Lima: Editorial El Virrey.

StePHENS, M. (2014). Comparative Housing Research: a "system-embedded" approach. En M. Norris Meaning and Measurement in Comparative Housing Research. London, Routledge.

THERBORN, G. (2015). Los campos de exterminio de la desigualdad. México: FCE.

TORREJÓN, L. (2010). Rebeldes republicanos: la turba urbana de 1912. Lima: Red para el desarrollo de las Ciencias Sociales. 